\title{
College students eating habits and knowledge of nutritional requirements.
}

\author{
Sam Abraham*, Brooke R. Noriega, Ju Young Shin \\ Bethel College School of Nursing, Bethel College, Mishawaka, Indiana, USA
}

\begin{abstract}
Background: Inadequate nutrition affects students' health and academic success. Students may have proficient knowledge regarding nutritional requirements; however, the transition to college life gives them more freedom to choose the type and the amount of food they eat. Most college campuses have dining facilities that provide a variety of food options, which can lead to establishing either good or bad eating behaviors.
\end{abstract}

Purpose: The purpose of this study was to examine college students' eating habits and knowledge of nutritional requirements for health.

Method: This was a quantitative, cross-sectional study, with a descriptive design.

Results: The students are knowledgeable that consuming fast food, soda, and processed food are unhealthy and they contain additives. They indicated strong agreement to keep themselves hydrated and choosing food because of taste preference. Even though majority admitted eating fresh fruits, a significant number consume processed food such as chips, cookies, and cereal based on convenience. Smartphone resources, vending machine use, and drinking soda were their least frequently used habits.

Conclusion: Students have a fair knowledge of nutritional requirements for health; however, food choices they make are not necessarily healthy. Convenience and taste of food were priority.

Keywords: Nutritional requirements, College students' health, Eating habits, College students' knowledge of food.

Accepted on January $17^{\text {th }}, 2018$

\section{Introduction}

\section{College students'eating habits and knowledge of nutritional requirements}

College students are at risk for making poor dietary choices that can cause significant health problems. Brown, O’Connor, and Savaiano [1] warned the transition to college causes significant changes in dietary options. Majority of undergraduate students eat at college dining facilities with limited healthy food options. Moreover, if students do not attain adequate nutrition daily, a decrease in academic or physical performance can result. The purpose of the present quantitative study was to investigate college students' eating habits and knowledge of nutritional requirements for health. Two research questions addressed were RQ1: What are college students' eating habits for health? and, RQ2: What is college students' knowledge of nutritional requirements for health?

Despite the strong emphasis on meeting nutritional requirements every day to achieve optimal health, many college students tend to care less about or neglect their nutritional requirements. Many factors come in to play as they transition to college life. Many of them leave the parental home, adapt to social and environmental changes, acknowledge new financial responsibilities, build different social networks, and experience different time availability [2]. Yet, meeting nutritional requirements remains important in achieving one's health. It is very beneficial for college students to formulize good eating habits that lead them to obtaining health and optimal function.

\section{Background}

As individuals transition from home to college life, nutritional knowledge becomes more important because food options change and dietary challenges arise. Traditional oncampus students use college dining facilities to eat meals. Students have the liberty of choosing a variety of healthy and unhealthy food options. O. Brown, noted "...those attending college can expect to gain 4-9 pounds in the first 2 years of college". If college students are unaware of the nutritional requirements to maintain a healthy body weight, they can make poor nutritional decisions, which can cause poor weight management and health problems.

Individuals entering college are beginning to live independently. Students' physical activity and eating habits usually shape or change during these years. Establishing good eating habits during this time is critical, because these behaviors often continue through adulthood and can be very difficult to change once they are established. O. Brown et al. stated, "overweight college students are more likely to become overweight adults and are at a higher risk for dietrelated chronic diseases such as cardiovascular disease, type 2 diabetes, some cancers, and hypertension". Educational interventions need to be addressed to help college students meet their daily nutritional requirements.

\section{Review of Literature}

Sources of data accessed for review included peer-reviewed studies mostly from EBSCOhost. All the articles used for this 
study were published from 2012 to 2015 . Keywords used to find relevant research articles are nutritional requirements, college students' health, eating habits, and college students' knowledge on food.

\section{Nutritional requirements}

It is crucial to meet daily nutritional requirements for one's body to function properly and to maintain one's health to the optimal level. Most nutritional values such as protein, energy, carbohydrates, fats and most minerals can be obtained by food sources. However, some individuals take dietary supplements on a daily basis to ensure their nutrition level. The current college-aged group should have had education on nutrition back in elementary school via the Food Pyramid. Also, since 2011, people have had access to MyPlate, which is a visual representation of nutrition requirements. Each nutrient plays an important role in establishing health, metabolism, and proper function of the body [1].

\section{College students' knowledge}

It is inevitable that college students face a new environment for meal preparation, planning, and eating as they transition to their college life. Even though many college-aged students are aware of the importance of meeting nutritional values, their knowledge and attitude might hinder them from changing their behavior. Many other factors come in to play in their decision-making, however, the college students' knowledge on nutrition does not always lead to healthy food choices. Stockton and Baker discovered college students do understand that consuming fast food can lead to disease; however, their knowledge was not a factor that influenced their food choices.

Interestingly, Stockton and Baker found that college students did not think the harm from fast food was related to calories but rather harmful chemicals and additives. The main concern the students had was not the number of calories they were taking, but the additives to their food. Also, the male college students consumed more fast food than female college students. Students thought that hamburgers were not harmful to their health [3].

\section{Eating habits}

Various poor eating habits have been noted among college groups in many recent studies. Brown et al. conducted an experiment in which they implemented interventions on vending machine sales on a university campus. They stated that many college students tended to select food according to convenience, taste, time, and price rather than nutritional values. Many college students tended to choose quick and tasty options, which were usually available through vending machines [4].

In a study on correlation between perceived parenting style and the eating practices of college freshmen, Barneset al. surveyed 264 college freshmen between the ages of 18 and 20 years. Through this survey, they found little evidence of the effect of parenting style on eating habits in a college group. About $44 \%$ reported that they had the same eating practice as they did before coming to college. The researchers concluded that parenting style did not affect the eating habits of college students as much as it does in the eating habit of children and youth [5].

\section{Weight management}

In a study to determine weight management knowledge in firstyear college students, Das and Evens surveyed 45 first-year students who were recruited using a cross-sectional method. They found that the reasons for weight gain among first-year college students were the changes in the social and physical environments, such as dietary intake including alcohol use, physical activity, stress, and sleep [2].

\section{Challenges}

Das and Evans discovered that men and women reported different types of barriers for maintaining health. Men's perceived barriers were limited access to healthier foods and gym supplies, not enough time for physical activity, large work overload, and lack of support from family and friends. On the other hand, women reported lack of time to exercise or eat healthy, inability to manage time, stress from different environments, and failure to prioritize weight management as their perceived barriers [2].

\section{Health promotion and healthy behaviors}

Healthy behaviors, such as physical activity, are often compromised among college students. Miller et al. conducted a survey on the effectiveness of a health promotion smartphone application for college students. The researchers noted that many undergraduate students had less than optimal health nor participated in healthy behaviors on a regular basis. They discovered that college students believed the application was beneficial and helpful in that it promoted healthy behaviors and raised awareness [6].

Many colleges in the United States provide nutrition-related courses for their students. Lockwood and Wohl studied the effectiveness of a lifetime wellness course on changing students' global self-efficacy, physical self-efficacy, and wellness behavior. The participants reported that the 15-week course had a significant impact on their behavior changes. More physical activity and exercise were initiated. Also, the students' food choices were more nutritious and healthier after the course [7].

Boucher et al. investigated an intervention to promote the consumption of fruits and vegetables among young adults in junior college. Consuming fruits and vegetables is one of the important healthy behaviors to achieve one's optimal physical function. The researchers found that the intervention increased the number of college students eating at least five servings of fruits and vegetables. They emphasized the importance of developing interventions tailored to college students to promote healthy behaviors [8].

Similar results were shown in another recent study. Texting has become one of the common communication tools in college-aged population. Brown et al. used text messaging in their study to provide nutrition education and inform better food choices in college students. They found out that college students had better understanding of nutrition and increased their fruit and vegetable consumption. Furthermore, text messaging appeared to be an effective education tool to enhance nutrition related knowledge and encourage healthy behaviors in college students [1]. 


\section{Conclusion drawn from literature review}

The researchers in the reviewed studies predominantly supported and demonstrated evidence for nutritional requirements, college student's eating habits, knowledge, weight management, barriers, healthy behaviors, and education. Many researchbased articles support that there is a need to investigate college students' eating habits and knowledge of nutritional requirements for health. There is a lack of knowledge in nutritional values among college students. Some students develop poor eating habits and tend to select food according to convenience, taste, time, and price available to them rather than their nutritional values [4]. Therefore, many college students struggle managing their weight as they gain more weight each year. Some barriers to healthy behaviors they reported are lack of time, lack of healthy food options, and lack of social support [2]. Various interventions such as text messaging, Smartphone application, and college courses appeared to be very beneficial in promoting healthy behaviors such as exercise and eating healthy food.

\section{Methodology}

This was a quantitative, cross-sectional study with a descriptive design. An approval from the Institutional Review Board (IRB) was attained before surveying college students. All participants were 18 years of age or older and currently attending college. The sample size was 121 college students. A convenient sampling method was used, because access was easy and all individuals were encouraged to participate.

The survey instrument was developed after a thorough review of the literature. The survey tool was thoroughly reviewed by the nursing faculty and peers to obtain face-validity. The demographics helped obtain information about the specific aggregate. The statements related to the research question and were directed to obtain information regarding college student's eating habits and knowledge of nutritional requirements for health. The survey included five demographic and 20 Likerttype survey statements. Statements 1-12 addressed RQ1 using the frequency scale never (1), rarely (2), every day (3), and more than once a day (4). Statements 13-20 addressed RQ2 using the agreement scale.

Permission was obtained to conduct the surveys outside the college Dining Commons. Participants had the freedom to answer survey questions before or after their meals. A table was set up with survey sheets and informed consents, as well as candy to help give individuals the initiative to participate in the study. Each individual willing to participate was given explanation regarding the informed consent and requested to sign it before completing the survey. The participants' names were not written on the survey document, therefore, keeping information confidential. Participants received a copy of the informed consent. Completed surveys and signed informed consents were collected separately in envelopes to ensure confidentiality.

\section{Results}

After collecting the required surveys, demographics and survey statements were analyzed using the quantitative measures. A total of 125 students took the survey. However, 4 survey responses were incomplete, and therefore, withdrawn from the data. The demographic results are displayed in percentages and frequencies in Table 1.

\section{Demographic characteristics}

The sample size of this study was 121 participants with $61 \%$ female students. All the participants were from ages 18-25. All 4 years in college were well represented with 20 or more from each year. Varieties of majors were represented in the study, among which, the business-related majors, health science, education, and sports majors dominated the group. For weight perception, 64\% reported they perceive they were at normal weight. About one-third indicated they were from 6 to $50+$ pounds overweight, whereas $7 \%$ perceived they were underweight (Table 1).

The various factors that contribute to college students' eating habits are displayed in Table 2. The habit with the highest frequency was "I keep myself hydrated with water $(\mathrm{M}=3.41$, $\mathrm{SD}=0.73)$. Other frequent habits included taste preference $(\mathrm{M}=3.23, \mathrm{SD}=0.57)$, eating fresh fruits $(\mathrm{M}=3.04, \mathrm{SD}=0.70)$, and consumption of processed food $(\mathrm{M}=2.72, \mathrm{SD}=0.66)$. The statement with which participants showed the least frequent habits was related to Smartphone resource use to find the right food to eat $(\mathrm{M}=1.51, \mathrm{SD}=0.78)$ (Table 2$)$.

The factors that contribute to college students' knowledge of nutritional requirements are displayed in Table 3. The statement with which the participants agreed most strongly was that fast food contains unhealthy additives $(M=3.56$, $\mathrm{SD}=0.60)$. Othe agreements included unhealthiness of fast

Table 1. Descriptive statistics for participant demographics and background.

\begin{tabular}{|c|c|c|c|}
\hline \multicolumn{2}{|c|}{ Variable } & f & $\%$ \\
\hline \multirow{2}{*}{ Gender } & Male & 47 & $39 \%$ \\
\hline & Female & 74 & $61 \%$ \\
\hline \multirow{2}{*}{ Age range } & $18-21$ & 102 & $84 \%$ \\
\hline & $22-25$ & 19 & $16 \%$ \\
\hline \multirow{4}{*}{ Class } & Freshmen & 29 & $24 \%$ \\
\hline & Sophomore & 32 & $26 \%$ \\
\hline & Junior & 40 & $33 \%$ \\
\hline & Senior & 20 & $17 \%$ \\
\hline \multirow{10}{*}{ Majors } & Business & 23 & $19 \%$ \\
\hline & Health Science & 19 & $16 \%$ \\
\hline & Education & 15 & $12 \%$ \\
\hline & Sports & 12 & $10 \%$ \\
\hline & Sociology & 9 & $7 \%$ \\
\hline & Arts and Design & 8 & $7 \%$ \\
\hline & Christian Religion & 8 & $7 \%$ \\
\hline & Criminal Justice & 6 & $5 \%$ \\
\hline & Sign Language & 6 & $5 \%$ \\
\hline & Other & 15 & $12 \%$ \\
\hline \multirow{7}{*}{ Weight Category } & Underweight & 8 & $7 \%$ \\
\hline & Normal & 78 & $64 \%$ \\
\hline & Overweight 6-10 lbs & 17 & $14 \%$ \\
\hline & Overweight $11-20 \mathrm{lbs}$ & 8 & $7 \%$ \\
\hline & Overweight $21-30 \mathrm{lbs}$ & 6 & $5 \%$ \\
\hline & Overweight 31-50 lbs & 0 & $0 \%$ \\
\hline & Overweight $51+$ lbs & 4 & $3 \%$ \\
\hline \multicolumn{4}{|c|}{ Note: $(\mathrm{N}=121)$} \\
\hline
\end{tabular}


food $(\mathrm{M}=3.30, \mathrm{SD}=0.63)$, drinking soda $(\mathrm{M}=3.28, \mathrm{SD}=0.70)$, and eating processed food $(\mathrm{M}=3.15, \mathrm{SD}=0.64)$. The statement with which participants showed the least level of agreement was that exercise is more important than the type of food they eat $(\mathrm{M}=2.40, \mathrm{SD}=0.77)$. The participants had a fair agreement that smartphones help to find the right food $(\mathrm{M}=2.75, \mathrm{SD}=0.65)$. An important note is that even the least agreed statements collectively had a mean of 2.5 or greater on a 4-point scale indicating that most students have knowledge in nutritional requirements for health (Table 3 ).

\section{Discussion}

Majority of the students have formed the habit of staying well hydrated, which is a good practice. Choosing food according to taste preference seems to be the hallmark of college students. An interesting finding was that a large number of students reported they ate fresh fruits frequently, while they also consumed processed food. This contradictory health practice may be because of the limited food options available on campus. Students consumed a lot of processed food; however, they tried to maintain their nutrition level by choosing fresh fruit options available to them. Even though participants reported that Smartphone can be used to find resources for healthy eating, very few used the source. Vending machine use, and drinking soda were their least frequently used habits, which indicates a positive health direction.

Table 2. What are college students eating habits for health?

\begin{tabular}{|c|c|c|}
\hline Variable & M & SD \\
\hline I keep myself hydrated with water. & 3.41 & 0.73 \\
\hline I choose food according to taste preference. & 3.23 & 0.57 \\
\hline I eat fresh fruits. & 3.04 & 0.7 \\
\hline $\begin{array}{l}\text { I consume processed food (such as chips, } \\
\text { cookies, cereal) }\end{array}$ & 2.72 & 0.66 \\
\hline I choose food according to convenience. & 2.66 & 0.61 \\
\hline I eat vegetable salads. & 2.55 & 0.76 \\
\hline $\begin{array}{l}\text { I tend to eat unhealthy food when I am } \\
\text { stressed. }\end{array}$ & 2.36 & 0.73 \\
\hline I tend to eat unhealthy food when I am happy. & 2.3 & 0.65 \\
\hline I consume fast food. & 2.07 & 0.41 \\
\hline I drink soda (regular or diet). & 1.85 & 0.81 \\
\hline $\begin{array}{l}\text { I eat food items purchased from a vending } \\
\text { machine. }\end{array}$ & 1.54 & 0.58 \\
\hline $\begin{array}{l}\begin{array}{l}\text { I use the Smartphone to find the right food to } \\
\text { eat. }\end{array}\end{array}$ & 1.51 & 0.78 \\
\hline
\end{tabular}

Note: $(\mathrm{N}=121)$. Items were rated on a 4-point Liker-type scale ranging from 1 (Never) to 4 (More than once a day), so higher means indicate higher levels of frequency.

Table 3. College students' knowledge of nutritional requirements.

\begin{tabular}{|c|c|c|}
\hline Variable & $\mathbf{M}$ & SD \\
\hline Fast food contains unhealthy additives. & 3.56 & 0.6 \\
\hline It is unhealthy to eat fast food. & 3.3 & 0.63 \\
\hline Drinking soda is unhealthy. & 3.28 & 0.7 \\
\hline It is unhealthy to eat processed food. & 3.15 & 0.64 \\
\hline Fresh salads are healthier than meat products. & 3.15 & 0.64 \\
\hline Excess calories in food are harmful to health. & 3.06 & 0.64 \\
\hline Smartphones help to find the right food. & 2.75 & 0.65 \\
\hline Exercise is more important than the type of food. & 2.4 & 0.77 \\
\hline
\end{tabular}

Note: $(\mathrm{N}=121)$. Items were rated on 4-point Liker-type scale ranging from 1 (Strongly Disagree) to 4 (Strongly Agree), so higher means show greater level of agreement.
Majority of the participants $(85.1 \%)$ reported that they rarely consume fast food. They also strongly agreed $(61.2 \%)$ that fast food contains unhealthy additives. This shows students acknowledge the unhealthiness of fast food and avoid consuming it on a regular basis. However, they claim to choose food based on taste, convenience, and food that is processed indicating unhealthy eating choices even though it is not necessarily from a fast food restaurant.

The relationship between the habit and knowledge of drinking soda was positive. A vast majority of participants $(81.8 \%)$ reported that they either rarely or never drink soda. Only a small number of participants (18.2\%) reported that they drink soda every day or more than once a day. When asked about their knowledge about unhealthiness of drinking soda, many participants $(87.6 \%)$ either agreed or strongly agreed. There is a positive correlation between their eating habit and knowledge indicating that students acknowledge the harmfulness and their behaviors reflect their knowledge.

There was a negative correlation between eating habit and knowledge in consuming processed food. More than half of the participants $(65.3 \%)$ indicated that they consume processed food either every day or more than once a day. However, $89.3 \%$ either agree or strongly agree with the statement that it is unhealthy to eat processed food. This finding reveals that many students understand that processed food is unhealthy; however, they continue consume a large amount of processed food every day.

Brown et al. discovered that college students often select food from vending machines and according to convenience, taste, time, and price instead of nutritional values. On the contrary, in the current study, college students did not frequently use vending machines on campus even though they reported choosing food based on convenience. Stockton and Baker had warned that college students' knowledge of nutrition does not always correlate with their eating habits because they consumed large amount of fast food even though they acknowledge its unhealthiness. In contrast, in the current study, responses from college students demonstrated low amount of fast food consumption, yet high level of knowledge of its harmfulness to their health. However, there was a high level of processed food consumption despite their knowledge in its negative effect on their health. Therefore, it can be concluded that high level of knowledge does not necessarily mean healthy eating behaviors.

\section{Limitations}

A limitation to this study was the small sample size of 121 participants in about 2000-student population. The college cafeteria is the main dining place on campus where most traditional undergraduate students who have on-campus meal plan eat every day. Non-traditional or commuters were underrepresented. Another limitation was that the responses could have been biased because students were already going or coming from eating at a buffet style location. Since this survey was gathering information regarding nutritional requirements, some students' responses might have differed compared to those students who would cook at home or in their dorm rooms. Generalization could be limited because this study was conducted in one Christian college in the mid-western United States. 


\section{Conclusion and Recommendations}

About one-third of college student participants reported that they were from 6 to $50+$ pounds of overweight. Even though students were knowledgeable about food containing additives, perils of fast food, unhealthiness of processed food and soda, they intermingled processed and fast food based on taste preference and convenience with fruits and salads. Although many participants showed good eating habits and adequate knowledge of nutritional requirements, the need was discovered to investigate further about different factors that contribute to their eating habits and their knowledge. In addition, it would be beneficial to research what health education practices can be placed to help guide their eating habits and promote overall health. Providing health, nutrition related courses and using technology as a means to educate the new generation could be effective and used for future learning.

\section{References}

1. Brown O, O’Connor L, Savaiano D. Mobile MyPlate: A pilot study using text messaging to provide nutrition education and promote better dietary choices in college students. J Am Coll Health. 2017;62:320-27.

2. Das B, Evans E. Understanding weight management perceptions in first-year college students using the health belief model. J Am Coll Health. 2014;62:488-97.

3. Stockton S, Baker D. College students' perceptions of fast food restaurant menu items on health. Am J Health Educ. 2013;44:74-80.

4. Brown M, Flint M, Fuqua J. The effects of a nutrition education intervention on vending machine sales on a university campus. J Am Coll Health. 2014;62:512-16.

5. Barnes S, Brown K, McDermott R, et al. Perceived parenting style and the eating practices of college freshmen. Am J Health Educ. 2012;43:8-17.

6. Miller T, Chandler L, Mouttapa M. A needs assessment, development, and formative evaluation of a health promotion smartphone application for college students. Am J Health Educ. 2015;46:207-15.

7. Lockwood P, Wohl R. The impact of a 15-week lifetime wellness course on behavior change and self-efficacy in college students. Coll Stud J. 2012;46:628-41.

8. Boucher D, Gagné C, Côté F. Effect of an intervention mapping approach to promote the consumption of fruits and vegetables among young adults in junior college: A quasiexperimental study. Psychology Health. 2015;30:1306-25.

\section{*Correspondence to:}

Sam Abraham, RN, MS, DHA

Assistant Professor of Nursing

Bethel College School of Nursing

Mishawaka

Indiana

USA

Tel: $269-240-7467$

E-mail: abrahams383@att.net 